\title{
A estética do confinamento no filme A Religiosa, de Jacques Rivette (1966)
}

\author{
Luiz Roberto Takayama
}

Universidade Federal de Lavras 


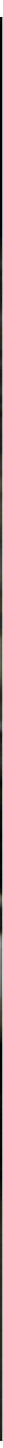


Gostaria de rememorar o início do filme. Letras brancas sobre um fundo negro, vê-se a imagem muda e estática de um texto escrito. Através dele, somos advertidos de que o filme, adaptação livre de um livro polêmico de Diderot, é uma obra de imaginação. Adaptação livre e obra de imaginação, desejaria chamar a atenção para essas duas definições triviais. Pois, o que gostaria de mostrar aqui é que o sentido que Rivette empresta a esses termos está, como seu filme, bem distante de ser trivial.

Como se sabe, uma obra de imaginação é tomada comumente como sinônimo de obra de ficção. E parece ser bem isso o que esse texto inicial nos induz a crer ao afirmar que o filme não pretende apresentar um retrato fiel das instituições religiosas do século XVIII ou de qualquer outra época. Contudo, os planos seguintes não demoram um instante sequer para nos desarmar e contradizer o que mal acabamos de ler.

Ao estilo de uma obra de não ficção, ou mais precisamente, ao de um verdadeiro documentário, ouve-se então a voz off de um narrador fazer uma breve apresentação de Diderot e de seu romance enquanto vemos um retrato seu; logo em seguida, nós a ouvimos descrever a vida nos conventos durante o século dezoito, ao mesmo tempo que se vê desfilar sobre a tela uma série de desenhos históricos sobre o tema. Somos então informados, pela mesma voz, de que, em seu romance, Diderot se inspira em personagens "reais": Louise Adelaïde d'Orléans, cujo retrato nos é dado observar, teria servido de modelo à madre superiora de Saint Eutrope; Marguerite Delamarre, da qual testemunhamos um impresso de seu fatídico Mémoire, teria sido a fonte para a "religiosa" de Diderot. Enquanto ouvimos um breve relato de sua vida seguido de uma citação de Bossuet, vemos uma ilustração da abadia de Longchamps sendo sucedida pela imagem da página de rosto de uma edição antiga do livro de Diderot; a ela se segue a foto da capa de uma edição mais recente do mesmo livro.

$\mathrm{Na}$ sequência, cessada a voz off do narrador, é-nos dado ver novamente a imagem de um texto igualmente escrito em letras 
brancas sobre um fundo negro. Trata-se de um sermão de Louis Bordalue sobre o dever dos pais em relação à vocação de seus filhos. Todavia, à diferença do primeiro, o texto, dessa vez, não é mais mudo; sua imagem é então acompanhada, para nossa surpresa, pelo que parece ser o rumor de vozes de uma plateia. Tal suspeita parece logo se confirmar, pois esse ruído é então sobreposto pelo som característico e tradicional nos palcos franceses das três batidas a anunciar que o espetáculo está prestes a começar.

É, aliás, o próprio Rivette que confessa ter utilizado esse detalhe sonoro como um meio para marcar a presença da representação teatral. Sob esse aspecto, menos sutil é seguramente a sequência que, a rigor, abre o filme. A maneira como nos são mostrados o público da cerimônia dos votos bem como a própria cerimônia nos remete infalivelmente a uma cena de teatro'. Trata-se mesmo de uma espécie de prólogo dramático servindo para nos introduzir ao tema, e que, não por acaso, se finda com o fechamento das cortinas sobre o espetáculo do desespero da heroína. Há, sem dúvida, uma relação estreita e importante do filme com o teatro, o que, de algum modo, nos conecta ainda mais intimamente com o universo de Diderot. Como se sabe, antes da realização do filme, o mesmo Rivette havia adaptado A Religiosa para o palco e, segundo o que ele próprio nos conta, tivera inicialmente, na ocasião, a intenção de filmar a peça:

Houve a montagem da peça e eu tive vontade de filmá-la e, por momentos, que ela se tornasse um filme, mas permanecendo inscrita no interior de uma representação teatral. [...] para mim, continuou sendo um filme sobre uma peça. (Aumont et al., 1968, p. 17)

1 Sobre marcar a presença do teatro no filme, Rivette responde: "Eu o fiz através de pequenas coisas: as três batidas no começo, a cena da abertura, onde quis que o público da cerimônia parecesse com um público de teatro e que a cerimônia fosse filmada como uma representação, coisas desse gênero." (AUMONT et al., 1968, p. 17). 
De toda maneira, gostaria ainda de voltar a chamar a atenção àquele inesperado som off das três batidas que anuncia o início do espetáculo e que acompanha a imagem do texto de Bordalue. Como nos mostra Chauderlot, num artigo que acompanhamos de perto, além de nos remeter à representação teatral, o som das batidas opera "uma transição entre o escrito e o visual, entre a experiência estática de leitura e a exposição dinâmica das imagens fílmicas" (Chauderlot, 2011). O que nos sugere pensar, de imediato, na relação entre a escrita e a imagem, entre o romance e o filme, em outras palavras, na própria adaptação cinematográfica da obra.

A imagem estática dos dois textos já citados assim como a imagem dos livros de Diderot nos convida a encará-los não somente como representações de algo escrito, mas principalmente como objetos visuais, na concretude mesma de suas presenças físicas. Impossível não se lembrar de Diário de um padre, filme de Robert Bresson, no qual o diário também é apresentado em toda sua materialidade, a imagem de um texto sendo escrito num caderno escolar.

A apresentação imagética dos textos, a aparição da presença física do livro enquanto objeto visual, tal se constitui como uma espécie de prefácio do que virá a ser a adaptação cinematográfica de Rivette. Pois, a nosso ver, o que o filme propõe é, mais do que recontar a história escrita por Diderot, materializar sua narrativa no espaço visual. Ou, em outras palavras, traduzir a experiência literária que o livro oferece a seu leitor em termos de imagens-movimento; e isso, como tentaremos mostrar, através de uma espécie de "estilização do espaço". Tal é o sentido de sua obra de imaginação, tal é a liberdade que se permitiu Rivette em sua adaptação.

Ora, o que chamamos de estilização do espaço anuncia-se já em ato, com toda sua força, desde a cena de abertura do filme, ou seja, desde a cena teatral dos votos de Suzanne Simonin: entre o palco da cerimônia e os espectadores - nós inclusive - interpõe-se algo chocante e mesmo brutal ao qual é impossível ficar in- 
diferente: uma grande grade cinza de barras verticais. É preciso dizer mais: essa grade a esquadrinhar toda tela, é ela que ocupa o primeiro plano recobrindo, de modo ostensivo, todo o desenrolar da cerimônia, os protestos patéticos da heroína, o seu desespero.

Essa cena inicial sintetiza exemplarmente, a nosso ver, a ideia do filme; ela funciona como uma espécie de fórmula a resumir o que Rivette nos propõe com sua adaptação. Pois, a imagem dessa grade cinza de barras verticais não é um símbolo nem uma metáfora, mas um dos elementos a compor a ideia cinematográfica da reclusão, do claustro, do confinamento. Se, nessa cena inicial, Rivette coloca essa imagem em primeiro plano, com toda sua visibilidade, relegando o próprio drama ao segundo plano, é porque quer tornar manifesto o que procura nos fazer entender como o tema principal de seu filme, tal como soube extrair do romance de Diderot: o confinamento.

O que não quer dizer, bem entendido, que o pathos de Suzanne Simonin perca importância no filme. Ao contrário, é sua paixão que conta; é ela que se trata de mostrar em toda a sua intensidade, tal como a narrativa de Diderot logra atingir no plano literário. Mas, é preciso dizer que essa mesma intensidade, o filme, no plano das imagens, só consegue alcançá-la através da composição da reclusão. As grades cinzas de barras verticais ao se interporem à nossa visão, funcionam não como um obstáculo, mas ao contrário, como lentes a nos revelar, com maior nitidez, o drama vivido pela religiosa.

Ora, essa ideia cinematográfica de reclusão ou de confinamento, Rivette a concebe não apenas pelo recurso às grades propriamente ditas - as quais aparecem, além de na cena inicial dos votos, no parlatório, na porta da capela, nas grades das janelas -, como também através da acentuada predominância de cenas de interiores. Com efeito, são bem escassas as sequências externas, e mesmo essas, excetuando-se uma ou outra, aparecem quase sempre como se fossem recintos fechados: que se tome como exemplo o jardim do primeiro convento onde as espessas folha- 
gens das árvores ao fundo formam uma verdadeira parede viva. A predominância de interiores, por si só, vem reforçar a condição de prisioneira da heroína: mesmo em "liberdade", em sua casa no início do filme, ou a trabalho no final, ao se encontrar sempre sob quatro paredes, sentimos que ela não se encontra menos enclausurada do que no convento.

Mas, é preciso acrescentar que mesmo os espaços internos recebem um tratamento de modo a potencializar a ideia e a sensação de confinamento. Em primeiro lugar, a recusa quase completa da profundidade de campo; em segundo lugar, a segmentação dos espaços que impede uma visão de conjunto ao nos mostrar somente fragmentos de corredores, de escadas, do quarto, da cela, do refeitório, da capela; e mais ainda, dentro desses espaços segmentados, encontramos, por diversas vezes, o corpo da heroína comprimido por outros corpos, quer seja pelas paredes dos corredores estreitos, pelos panos brancos da lavanderia, ou então pelos corpos das outras irmãs - por exemplo, nas cenas em que Suzanne canta e toca cravo; na capela, e, no refeitório, ao ser pisoteada num determinado momento, ou então sendo assediada pela madre superiora do segundo convento.

Além disso, a maneira como a iluminação é trabalhada no filme serve também para diminuir os espaços deixando amplos volumes na penumbra, ao mesmo tempo em que faz ressaltar, por contraste, as partes brancas dos véus que circundam os rostos das irmãs.

No chiaroscuro das cenas interiores, as cabeças das irmãs parecem estar separadas do resto de seus corpos pelo brilho da roupa e do véu de seus hábitos. Suas faces são virtualmente divididas em duas pela faixa branca horizontal que atravessa suas frontes. A manipulação da luz por Rivette mantém a maior parte dos volumes circundantes na escuridão ou numa sombra cinza, borrando seu conteúdo, enquanto, por contraste, todos os elementos brancos aparecem nitidamente circunscritos, ainda mais destacados de uma sinistra massa azulada evocativa das não discerníveis mas poderosas forças latentes que habitam atmosferas góticas. (Chauderlot, 2001) 
O confinamento também se faz sentir algumas vezes pela sonoplastia: no primeiro encontro da heroína com sua mãe na escada da residência, enquanto elas conversam, ouvimos o barulho de uma charrete ou de uma carruagem puxada por cavalos; no segundo encontro, no quarto de sua mãe, ouvimos os ruídos noturnos de insetos culminando com sons intensos de sinos; ainda cativa no quarto de sua casa, enquanto borda ao lado da janela, ouvimos o barulho de crianças brincando; quase uma repetição dessa mesma cena, dessa vez na cela do convento, vemos Suzanne também sentada ao lado da janela lendo os salmos em voz alta e sendo interrompida pelo som de risadas femininas. Em outros momentos podemos ouvir o barulho de água escorrendo, de trovoada, de ventania. Ora, todos esses sons, ao trazerem à tona a realidade de um mundo exterior próximo e distante ao mesmo tempo, só fazem aumentar, por contraste, a sensação de isolamento dos recintos fechados nos quais eles invadem.

Por outro lado, poderíamos objetar, se é que se trata mesmo de uma objeção, que há muito movimento nesses espaços. E, de fato, constatamos uma intensa movimentação dos personagens, muito embora a câmera se mantenha estática em várias tomadas, ou então com movimentos lentos e sutis na maior parte do tempo. No entanto, os movimentos de Suzanne Simonin, principalmente no primeiro convento, não a levam em parte alguma, tornando-se errância num beco sem saída.

É, portanto, toda uma "estética do confinamento", se podemos chamá-la assim, que é colocada em prática por Rivette em seu filme. Ora, é essa mesma estética que se encontra, por exemplo, na obra de Vermeer, na qual se evidencia um processo deliberado de encarceramento²; na pintura contemporânea de Francis Bacon, onde suas figuras se encontram quase sempre dispostas em

2 É o que nos ensina, entre outras coisas, Jean Paris (1973) ao nos mostrar o confinamento a que o pintor holandês submete suas figuras. 
espaços internos e delimitadas por traços geométricos; e também no cinema de Robert Bresson. Mas, enquanto que em sua obra o tema do confinamento e a fragmentação do espaço são concebidos para impedir a representação (Bresson, 2005, p. 74), em A Religiosa de Rivette, ao contrário, eles se colocam ao serviço dela.

Pois, com o confinamento dos personagens, tal como praticado, o filme não faz senão aproximar-se ainda mais da representação cênica. E essa aproximação com o teatro reforça-se ainda mais pela predominância dos planos médios e planos americanos - embora, é verdade, não encontremos planos de conjunto - e também pela ausência de primeiríssimo plano ou do close fechado sobre o rosto dos personagens, tal como encontramos, por exemplo, na Paixão de Joana d'Arc de Carl Th. Dreyer.

Talvez seja essa uma das razões de muitos considerarem um tanto quanto fria a expressão dramática d'A Religiosa e que poderia realmente se intensificar se lançasse mão dos recursos próprios do cinema para esse fim, tal como aqueles que emprega o cineasta dinamarquês em seu filme. Trata-se, pois, de um risco calculado que Rivette assume na sua intenção declarada de aproximar sua obra da representação teatral através do encarceramento de seus personagens.

Mas, é preciso observar que essa estética do confinamento concebida por Rivette não se reduz a uma questão técnica. Trata-se mesmo de como o cineasta compreende e traduz a obra e o sentido da crítica de Diderot. É a clausura conservada por algumas instituições religiosas de seu tempo e não a religião considerada de modo geral e abstratamente que produz suas vítimas: e são vítimas tanto a perseguida Suzanne Simonin como suas algozes, irmãs que se transformam em um bando de animais selvagens, ou então em seres que acabam na loucura tomadas pela concupiscência.

Alguns criticam o fim "forçado" que Rivette concebe à sua adaptação. De nossa parte, cremos que, se não é a melhor maneira de terminá-lo, é pelo menos coerente, pois o fim do drama 
vivido pela religiosa coincide, no final das contas, com o fim de seu confinamento.

\section{Referências bibliográficas}

AUMONT, J.; COMOLLI, J.-L; NARBONI, J.; PIERRE, S. “Le Temps déborde, entretien avec Jacques Rivette”, Cahiers du Cinéma, n. 204, p. 6-21, sep. 1968.

BRESSON, R. Notas sobre o cinematógrafo. Tradução de Evaldo Mocarzel e Brigitee Riberolle. São Paulo: Iluminuras, 2005. CHAUDERLOT, F.-S. "Becoming Image": Deleuzian echoes in Jacques Rivette's "La Religieuse”. Disponível em http:// www.jacques-rivette.com/. Publicado originalmente em Eighteenth-Century Life, 23, p. 88-100, Winter 2001.

PARIS, J. Miroirs de Rembrandt, le sommeil de Vermeer, le soleil de Van Gogh, espaces de Cézanne. Paris: Galilée, 1973. 